\title{
Complete Regrowth of Beard Hair with Ruxolitinib in an Alopecia Universalis Patient
}

\author{
Yuval Ramot Abraham Zlotogorski \\ Department of Dermatology, Hadassah-Hebrew University Medical Center, Jerusalem, Israel
}

\section{Established Facts}

- Alopecia areata (AA), and especially the more severe types, alopecia totalis and universalis, can lead to profound psychological sequelae.

- The psychological and social consequences of AA can be more severe in religious populations in which the hair has a special significance.

\section{Novel Insights}

- Ruxolitinib, a Janus kinase inhibitor, can lead to rapid and significant hair regrowth, even in chronic alopecia universalis.

- Such treatment can significantly improve the quality of life of patients for whom the hair bears special religious significance.

\section{Keywords}

Alopecia areata · Alopecia · Hair · Ruxolitinib - Janus kinase inhibitors

\footnotetext{
Abstract

While most alopecia areata (AA) cases resolve spontaneously, the more severe types of AA, alopecia totalis (AT) and alopecia universalis (AU), can be highly resistant to therapy. We report on a 33-year-old ultraorthodox Jewish man with an 11-year history of AA that resulted in complete loss of the scalp and body hair 7 years ago. Previous treatments with intralesional and systemic corticosteroids had only partial
}

and temporary effects. The patient was treated with ruxolitinib, 20 mg twice daily, resulting in complete growth of the beard after 4 months of treatment. The beard has a special significance for ultraorthodox Jews, and loss of the beard hair can have marked social and psychological consequences in AA patients. The Janus kinase (JAK) inhibitors have recently emerged as an effective treatment modality in AA, including the more severe forms, such as AT or AU. This report highlights the beneficial effects of the JAK inhibitors, especially in populations where the hair has a special importance due to cultural and religious backgrounds.

(c) 2017 S. Karger AG, Basel

\section{KARGER}

(C) 2017 S. Karger AG, Basel

E-Mail karger@karger.com

www.karger.com/sad
Abraham Zlotogorski

Department of Dermatology

Hadassah-Hebrew University Medical Center

PO Box 12000, Jerusalem 9112001 (Israel)

E-Mail zloto@cc.huji.ac.il 


\section{Introduction}

Alopecia areata (AA) is a common autoimmune condition leading to nonscarring hair loss, affecting approximately $2 \%$ of the US population $[1,2]$. The most common form of AA is the patchy type, characterized by oval areas of hair loss, which usually resolve spontaneously. The more severe types of AA include alopecia totalis (AT), leading to complete loss of scalp hair, and alopecia universalis (AU), resulting in complete loss of scalp and body hair.

There are currently no approved medications for treating AA. Localized patches are usually treated with topical or intralesional steroids [3], and the more severe types can be treated with systemic corticosteroids [4]. Nevertheless, both AT and AU are often highly resistant to treatment, and hair growth is usually temporary and limited. Therefore, there is a strong medical need for effective treatment options for AA patients.

\section{Case Report}

We evaluated a 33-year-old ultraorthodox Jewish man with an 11-year history of gradual hair loss that resulted in complete loss of the scalp and body hair 7 years ago. Previous treatments with intralesional and systemic corticosteroids led to only partial and temporary growth of hair. The medical history was otherwise unremarkable.

Examination revealed complete loss of hair from the body and scalp, including the beard area (Fig. 1a). Treatment was initiated with ruxolitinib, $20 \mathrm{mg}$ twice daily, leading to regrowth of hair and resulting in complete growth of the beard after 4 months of treatment (Fig. 1b). Partial regrowth of scalp hair was also noted. The patient has now been treated for 1 year with ruxolitinib and is maintaining full beard hair and 50\% of scalp hair.

\section{Discussion}

Alopecia areata can lead to significant psychological and social sequelae in many patients. A higher prevalence of depression, anxiety, poor self-esteem and body image, social phobias, and paranoid disorders have been reported, resulting in a reduced quality of life [5-8]. While it is usually believed that the extent of hair loss is the best predictor of the severity of distress the patients will experience [7], for some populations, it is more a question of location than extent of hair loss determining the psychological effects. Loss of beard hair can have a more significant impact in some populations, as unshaved beard is important in expressing specific religious norms, such as in some Islamic societies and for orthodox and ultraorthodox Jews [9]. Although AA of the beard is a common entity in clinical practice $[10,11]$, it is interesting to note that its psychological and social effects have not been specifically studied. In our patient, being an ultraorthodox Jewish man, the loss of the beard hair had a significant effect on the social life of the patient, urging us to try newer treatment options.

Janus kinase (JAK) inhibitors are oral anti-inflammatory and antiproliferative medications, which block cy-
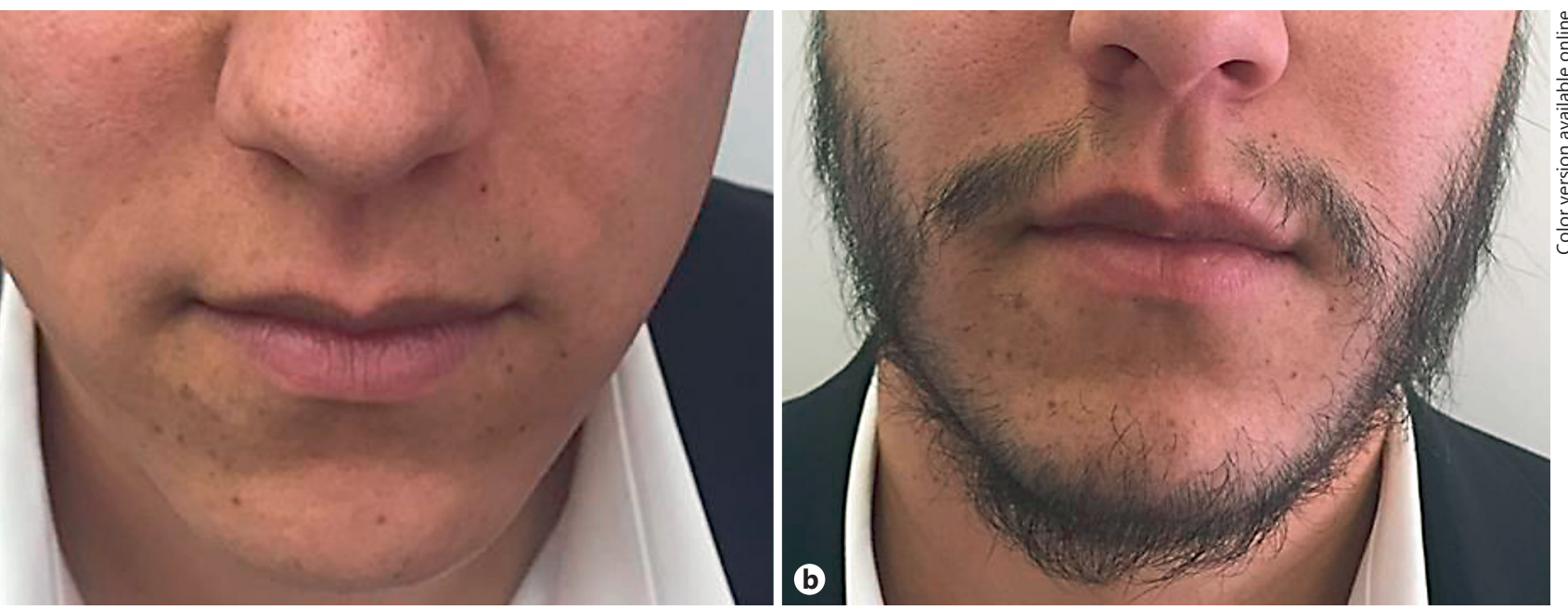

Fig. 1. a Complete hair loss in a 33-year-old ultraorthodox Jewish man. b The same patient after 4 months of treatment with ruxolitinib, demonstrating complete regrowth of beard hair. 
tokine signaling by inhibiting downstream cytoplasmic receptors [12]. They have been shown to be effective in several dermatological conditions, such as psoriasis, vitiligo, atopic dermatitis, graft versus host disease, and lupus erythematosus [13]. One of the most promising conditions for which JAK inhibitors were found to be effective is AA. Most of the studies performed on AA patients showed the effectiveness of the JAK $1 / 3$ inhibitor tofacitinib for treating AA $[14,15]$, and 1 patient was treated with the JAK $1 / 2$ inhibitor baricitinib with excellent results [16].

Ruxolitinib is a JAK $1 / 2$ inhibitor approved for the treatment of myelofibrosis and polycythemia vera [13]. Several studies have shown its effectiveness in the treatment of AA, and it was also found to be beneficial for the more severe types, AT and AU [17-19]. The current report further highlights the effectiveness of the JAK in- hibitors to treat AA, also in recalcitrant and chronic cases. It also emphasizes the importance of achieving hair regrowth in populations where the beard has a special importance due to cultural and religious backgrounds. Our patient experienced significant enhancement in his social life and his well-being, resulting in improved quality of life; this is in spite of the fact that the improvement was noted mainly in the beard area and not the scalp.

\section{Statement of Ethics}

A written consent was obtained from the patient.

\section{Disclosure Statement}

The authors have no conflicts of interest to disclose.

\section{References}

1 Biran R, Zlotogorski A, Ramot Y: The genetics of alopecia areata: new approaches, new findings, new treatments. J Dermatol Sci 2015;78: 11-20.

2 Safavi KH, Muller SA, Suman VJ, Moshell AN, Melton LJ 3rd: Incidence of alopecia areata in Olmsted County, Minnesota, 1975 through 1989. Mayo Clin Proc 1995; 70:628633.

3 Chang KH, Rojhirunsakool S, Goldberg LJ: Treatment of severe alopecia areata with intralesional steroid injections. J Drugs Dermatol 2009;8:909-912.

4 Shreberk-Hassidim R, Ramot Y, Gilula Z, Zlotogorski A: A systematic review of pulse steroid therapy for alopecia areata. J Am Acad Dermatol 2016;74:372-374.e1-e5.

5 Aschenbeck KA, McFarland SL, Hordinsky MK, Lindgren BR, Farah RS: Importance of group therapeutic support for family members of children with alopecia areata: a crosssectional survey study. Pediatr Dermatol 2017;34:427-432.

6 de Hollanda TR, Sodre CT, Brasil MA, Ramos ESM: Quality of life in alopecia areata: a casecontrol study. Int J Trichology 2014;6:8-12.

7 Hunt N, McHale S: The psychological impact of alopecia. BMJ 2005;331:951-953.
8 Tucker P: Bald is beautiful?: the psychosocial impact of alopecia areata. J Health Psychol 2009; 14:142-151.

9 Bromberger C: Hair: from the West to the Middle East through the Mediterranean. J Am Folklore 2008;121:379-399.

10 Cervantes J, Fertig RM, Maddy A, Tosti A: Alopecia areata of the beard: a review of the literature. Am J Clin Dermatol 2017, Epub ahead of print.

11 Saceda-Corralo D, Grimalt R, FernandezCrehuet P, Clemente A, Bernardez C, GarciaHernandez MJ, Arias-Santiago S, RodriguesBarata AR, Rodriguez-Pichardo A, GarciaLora E, Jaen P, Camacho FM, Vano-Galvan S: Beard alopecia areata: a multicentre review of 55 patients. J Eur Acad Dermatol Venereol 2017;31:187-192.

12 Renert-Yuval Y, Guttman-Yassky E: A novel therapeutic paradigm for patients with extensive alopecia areata. Expert Opin Biol Ther 2016;16:1005-1014.

13 Shreberk-Hassidim R, Ramot Y, Zlotogorski A: Janus kinase inhibitors in dermatology: a systematic review. J Am Acad Dermatol 2017; 76:745-753.e19.

14 Kennedy Crispin M, Ko JM, Craiglow BG, Li S, Shankar G, Urban JR, Chen JC, Cerise JE, Jabbari A, Winge MC, Marinkovich MP, Christiano AM, Oro AE, King BA: Safety and efficacy of the JAK inhibitor tofacitinib citrate in patients with alopecia areata. JCI Insight 2016;1:e89776
15 Liu LY, Craiglow BG, Dai F, King BA: Tofacitinib for the treatment of severe alopecia areata and variants: a study of 90 patients. J Am Acad Dermatol 2017;76:22-28.

16 Jabbari A, Dai Z, Xing L, Cerise JE, Ramot Y, Berkun Y, Sanchez GA, Goldbach-Mansky R, Christiano AM, Clynes R, Zlotogorski A: Reversal of alopecia areata following treatment with the JAK1/2 inhibitor baricitinib. EBioMedicine 2015;2:351-355

17 Harris JE, Rashighi M, Nguyen N, Jabbari A, Ulerio G, Clynes R, Christiano AM, MackayWiggan J: Rapid skin repigmentation on oral ruxolitinib in a patient with coexistent vitiligo and alopecia areata (AA). J Am Acad Dermatol 2016;74:370-371.

18 Mackay-Wiggan J, Jabbari A, Nguyen N, Cerise JE, Clark C, Ulerio G, Furniss M, Vaughan $\mathrm{R}$, Christiano AM, Clynes R: Oral ruxolitinib induces hair regrowth in patients with moderate-to-severe alopecia areata. JCI Insight 2016;1:e89790.

19 Vandiver A, Girardi N, Alhariri J, Garza LA: Two cases of alopecia areata treated with ruxolitinib: a discussion of ideal dosing and laboratory monitoring. Int J Dermatol 2017;56: 833-835. 